\title{
Estudo sobre qualidade de espaços públicos para a infância a partir da aplicação da Metodologia Ergonômica para o Ambiente Construído na Praça Luiza Távora em Fortaleza
}

\author{
Study on public space quality for infancy through the application of \\ Methodology of Ergonomic Assessment of the Built Environment in \\ Luiza Távora Square in Fortaleza
}

ALANA VASCONCELOS

Mestranda em Arquitetura e Urbanismo; PPGAU+D-UFC; alanaavasconcelos@gmail.com

VILMA VILLAROUCO

Dra. em Engenharia, PPGDesign e PPErgo-UFPE; PPGAU+D-UFC; vvillarouco@gmail.com

MANUELA LIMA

Mestranda em Arquitetura e Urbanismo; PPGAU+D-UFC, manucml@gmail.com

ZILSA SANTIAGO

Doutora, PPGAUD/Universidade Federal do Ceará, zilsa@arquitetura.ufc.br

AURISEU PINHEIRO

Mestranda em Arquitetura e Urbanismo; PPGAU+D-UFC; auriseunogueira@gmail.com

\section{RESUMO}

A convivência em espaços públicos nas zonas nobres das grandes cidades vem sendo progressivamente abandonada devido a diversos fatores, dentre eles o medo social e a ocupação com uso excessivo de tecnologias portáteis. A relação das crianças com o meio urbano vem enfraquecendo e isso pode vir a se tornar prejudicial tanto para o desenvolvimento neuropsicomotor destas, como para o senso e a forma de apropriação da cidade. A partir desta reflexão, foi identificada na cidade de Fortaleza, a Praça Luiza Távora como um espaço público que recebe intensa atividade de ocupação, mesmo estando inserida no contexto de bairro nobre. A partir da aplicação da Metodologia Ergonômica para o Ambiente Construído (MEAC) a pesquisa se propõe a explorar aspectos físicos e de percepção do usuário que indicam que a motivação deste tipo de uso se dá por ser um espaço acessível, lúdico e seguro. No decorrer do processo foi identificada a dificuldade em 


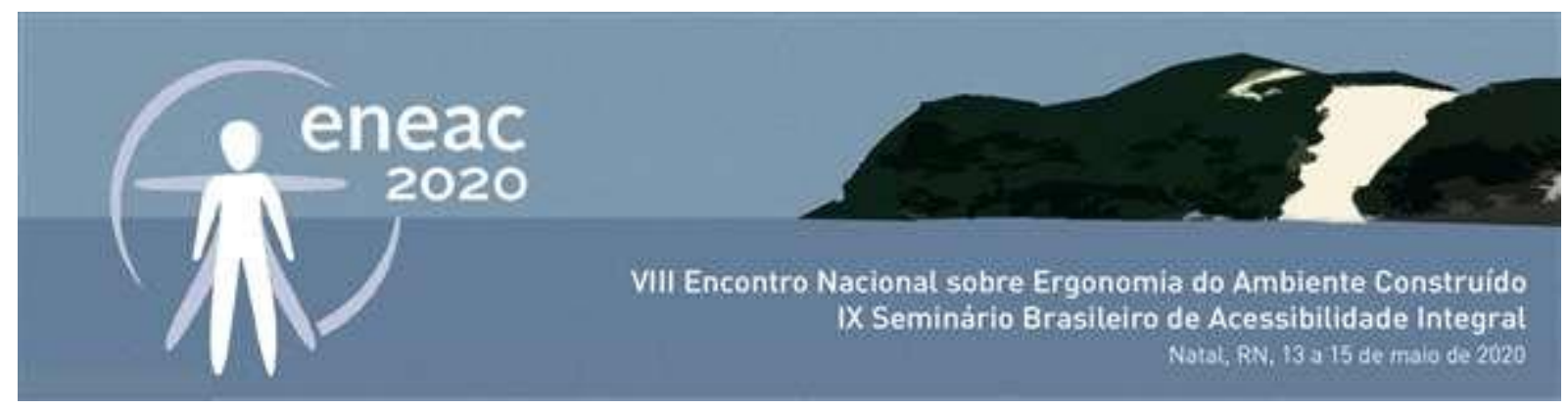

incluir crianças abaixo de sete anos no processo pleno de participação, sendo indicado como sugestão de tema para futuras pesquisas.

PALAVRAS-CHAVE: praça; ergonomia; MEAC; criança.

\section{ABSTRACT}

Coexistence in public spaces in large cities' noble areas has been progressively abandoned due to numerous factors, among them social fear and occupation with excessive use of portable technologies. The relationship between children and urban environment has become weaker and this may became harmful not only to their neuropsychomotor development, but also to their sense and form of city appropriation. Through this reflection, Luiza Távora Square has been identified in the city of Fortaleza as a public space which receives high occupation activity, even though it is inserted in the context of a noble neighborhood. Through the application of the Methodology of Ergonomic Assessment of the Built Environment (MEAC), this research has as its goal to explore physical aspects and user's perception which would indicate that the motivation for this type of use comes from it being and accessible, ludic and secure space. During this process, a difficulty was identified in including children below seven years old in full participation process, that being indicated as a theme suggestion for future researches.

KEYWORDS: square; ergonomic; MEAC; children.

\section{INTRODUÇÃO}

Nos dias atuais vem crescendo a potencialização do medo social, que induz a sociedade a uma situação de confinamento na aquisição de hábitos que reduzem ao máximo o contato com o meio externo. Shoppings para o lazer e carros para o transporte são sinônimos de segurança, enquanto o contato com espaço público é visto como arriscado. Neste contexto, a forma de educar as crianças sofre drasticamente, pois, elas são cada vez mais limitadas a brincar em espaços fechados e/ou com equipamentos eletrônicos.

Enquanto isso, espaços livres possuem o potencial de proporcionar conexão com a diversidade social, desenvolvimento de habilidades psicomotoras, contato com elementos naturais, criação de vínculos afetivos e estímulo à apropriação do meio urbano. Segundo Korpela (2011), a falta de acesso a estes espaços e sua não utilização são prejudiciais à saúde e à maturação infantil, sobretudo pela redução de mobilidade e atividade física das crianças.

O medo social vem alterando profundamente o território e o tecido urbano e, consequentemente, a vida cotidiana da população. Ameaças reais, contrapostas a ameaças potenciais típicas do imaginário singular coletivo, produzido pelos índices perversos do crescimento da violência nas cidades. Isso se agrava pela forma como esses índices são veiculados e tratados pela mídia, pela fala corriqueira do crime e, principalmente, pela ineficiência e impunidade no papel da polícia e do Estado frente à questão social. (BAIERL, 2004, p.20)

As praças são espaços de lazer de acesso democrático que, segundo Alex (2008), acompanham o desenvolvimento das cidades. Entretanto, muitos espaços públicos da cidade de Fortaleza estão 


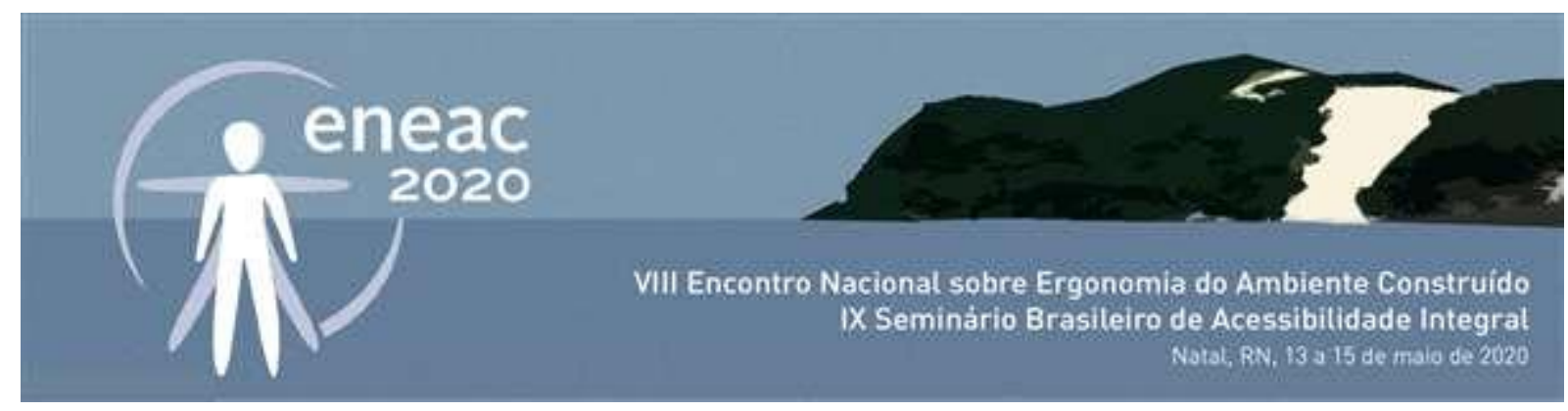

degradados e/ou sem atratividades. Assim, a escolha da Praça Luiza Távora como protagonista deste trabalho se justifica por ser uma das poucas praças da região nobre de Fortaleza onde é possível ver público assíduo e de várias idades com um forte senso de pertencimento. As crianças brincando livremente é um fator de especial atenção por ser uma prática incomum em outros pontos do bairro Aldeota.

Através da aplicação da Metodologia Ergonômica para Ambiente Construído (MEAC), objetiva-se explorar os aspectos ergonômicos que possam justificar o comportamento peculiar da sociedade para com o lugar. Apesar de ser uma metodologia mais frequentemente aplicada a espaços internos, o presente trabalho se propõe a aplicar no meio urbano, estabelecendo como foco o público infantil que utiliza o espaço com grande frequência.

\section{METODOLOGIA}

A presente pesquisa tem caráter exploratório e, a partir da aplicação da Metodologia Ergonômica para o Ambiente Construído (MEAC) proposta de Villarouco (2008) se propõe a compreender o sistema ambiente-homem-atividade, a qual envolve cinco etapas: Análise Global do Ambiente, a partir de uma abordagem macro, será utilizado o walkthrough para registrar as primeiras impressões do lugar; Identificação da Configuração Ambiental, através de levantamento de dados de dimensionamento, iluminação, ruído, temperatura, layout, segurança e acessibilidade; Avaliação do Ambiente em Uso envolve observações cuidadosas da execução das atividades por parte dos frequentadores do recorte espacial através do uso de registros de imagens, aplicação do método Mapa Comportamental e atenção às questões antropométricas; Percepção Ambiental do Usuário irão ser utilizadas as ferramentas Constelação de Atributos e Poema dos Desejos para acessar a opinião de pais e crianças sobre a Praça em estudo; Diagnóstico Ergonômico e Recomendações do Ambiente consiste na compilação dos resultados e das suas respectivas sugestões para atingir a melhoria técnica do espaço.

\section{RESULTADOS E DISCUSSÕES}

\subsection{Análise Global do Ambiente}

O estudo foi realizado na praça pública Luiza Távora, localizada no bairro Aldeota, na cidade de Fortaleza/CE. O espaço ocupa aproximadamente $18.235 \mathrm{~m}^{2}$, não possuindo barreiras físicas que limitem o horário de utilização (Figura 1). A escolha deste espaço público se deu por ter sido identificado, de forma empírica, um forte senso de apropriação da população para com o lugar, principalmente pelo fator de haver a presença de crianças brincando livremente. Desta forma, foi despertado o interesse em explorar quais seriam os fatores que favorecem esse tipo de relação com a cidade. 


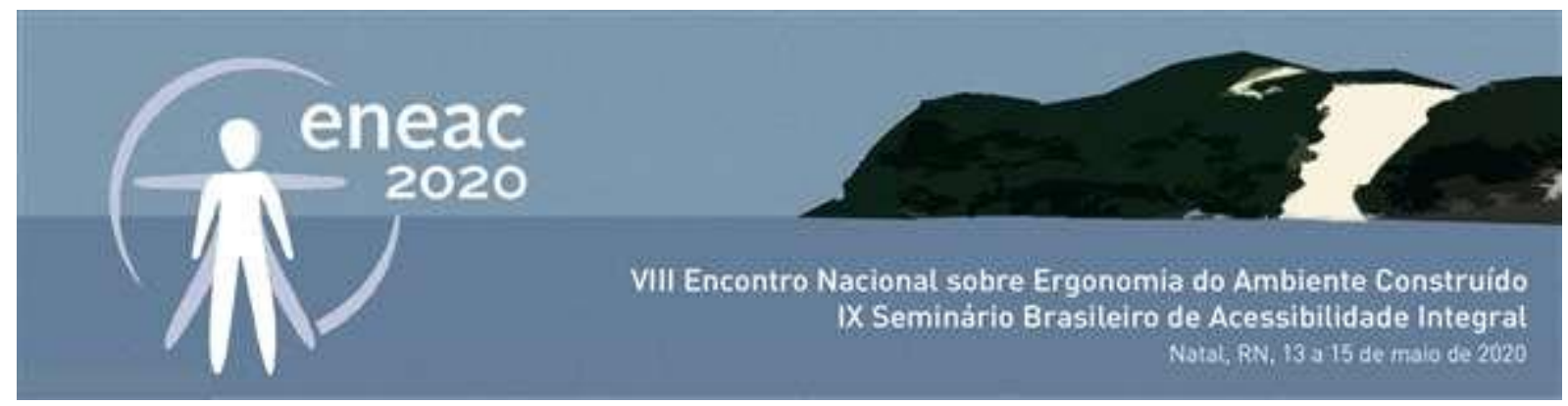

Figura 1: Planta baixa Geral

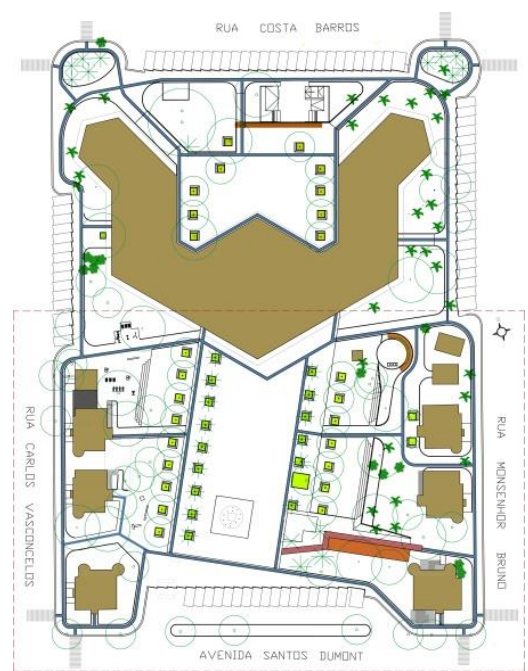

Fonte: Superintendência de Obras Pública do Ceará, trabalhado pelos autores (2020).
Figura 2: Planta baixa do recorte estudado

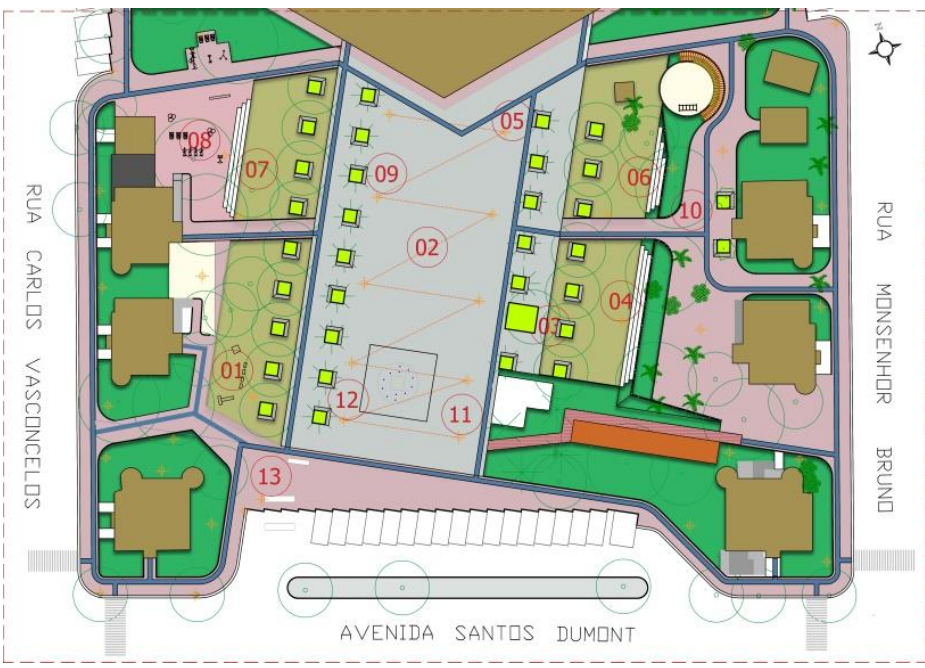

Fonte: Superintendência de Obras Pública do Ceará, trabalhado pelos autores (2020)

O método do walkthrough, idealizado e aplicado por Kevin Lynch (1960), foi adotado como ferramenta para anotação da percepção do pesquisador e seu entendimento sobre o ambiente. Método este que permite identificar, descrever e hierarquizar quais aspectos deste ambiente ou de seu uso merecem estudos mais aprofundados e quais técnicas e instrumentos devem ser utilizados.

Como resultado da aplicação, foram registradas as seguintes impressões: um espaço agradável que transmite sensação de segurança, limpeza, amplitude e aconchego; um lugar que apresenta composições espaciais que permitem diversos tipos de uso; uma praça bem iluminada natural e artificialmente, possuindo paisagismo harmonioso e mobiliário urbano estrategicamente distribuído e executado com materiais resistentes. A praça apresenta, também, edificações antigas bem preservadas que assumem função de órgãos governamentais, intervenções lúdicas que remetem à arte local, um centro de artesanato implantado no centro geográfico da praça com uma permeabilidade visual e física bem incorporada ao lugar (parte que não entrará no restante da análise no recorte espacial); um espaço com amplas áreas de circulação com pavimentação regular, presença de rampas e de piso tátil, demonstrando-se um espaço aparentemente acessível.

Observando a parte mais utilizada da praça pelo público infantil, o estudo concentrou-se no recorte espacial delimitado na Figura 2; a fim de aprofundar a análise ergonômica deste trecho.

\subsection{Avaliação da configuração ambiental}

\subsubsection{Layout e mobiliário}

Tendo como foco a perspectiva da criança no espaço público, elementos lúdicos ganham destaque na análise. A praça conta com uma pequena área de playground (Figura 3) composta por 03 mobiliários em fibra (escorregador, obstáculos em forma de cobra gigante e um tubo em forma de elefante). 0 


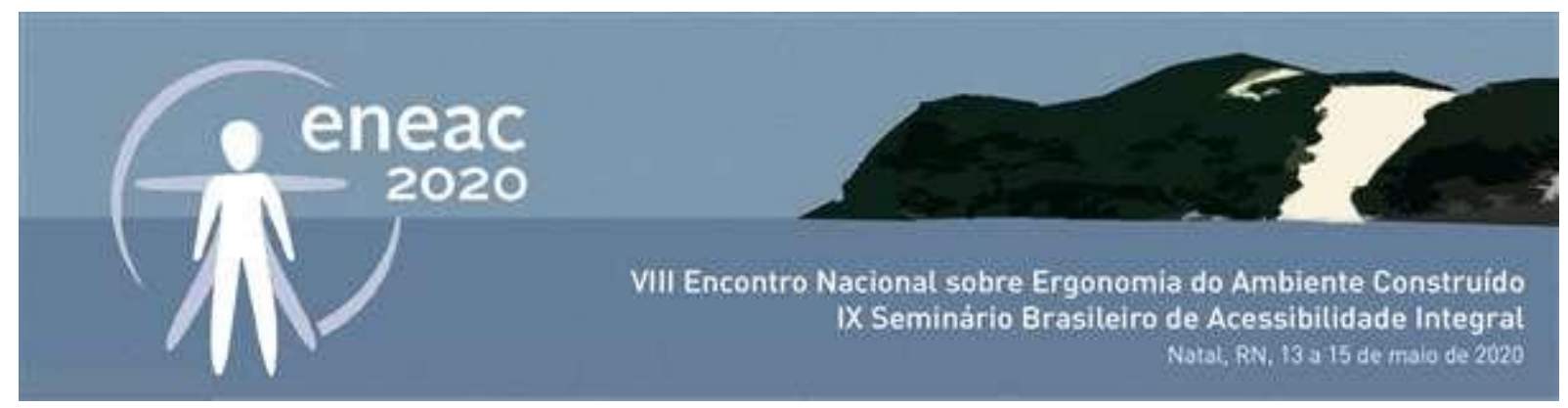

local é semicoberto por árvores de médio e grande porte como plumerias, jeriquitis, flamboyants, casuarinas e mangueiras. Estas espécies estão espalhadas por toda a praça, inclusive na parte infantil. As plumerias, que possuem troncos e galhos tortuosos, são mais um tipo de brinquedo para as crianças; pois, elas podem subir facilmente e de maneira segura devido aos crochês que as envolvem.

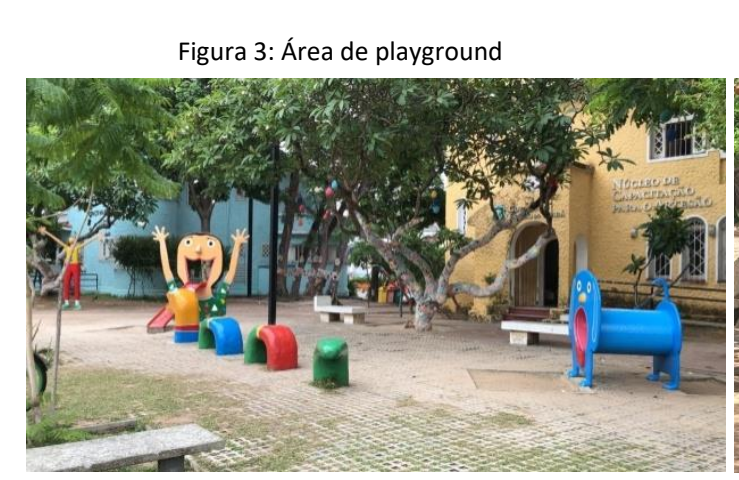

Fonte: Arquivo pesquisa.

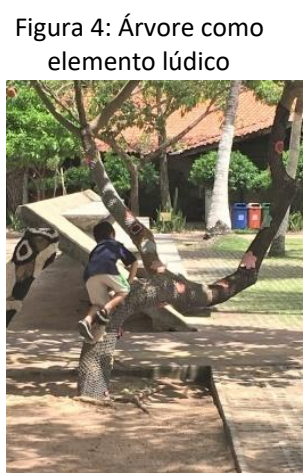

Fonte: Arquivo pesquisa.
Figura 5: Arquibancada como elemento lúdico

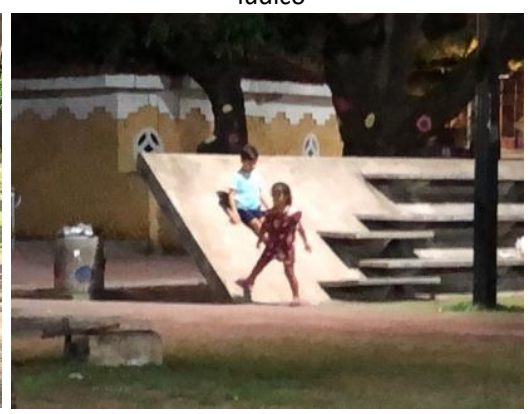

Fonte: Arquivo pesquisa.

É curioso observar que outros elementos assumem a função de brinquedos como é o caso das árvores (Figura 4), das arquibancadas (Figura 5), da rampa do vagão de trem (temporariamente desativado), da fonte de água (também desativada), da academia ao ar livre, dos próprios bancos e do amplo espaço central. Este último trata-se da área mais requisitada por crianças e jovens, pois, é onde elas andam de bicicleta, patins e patinete, além de poderem correr livremente.

Sobre a pavimentação da praça, identifica-se ser formada por três tipos de revestimentos (Figura 6): piso em granito flameado, placas de concreto e intertravado piso grama. Este último permite o nascimento da vegetação de forração que, somado às sombras das árvores propicia um local mais agradável para o uso do público em geral, independente do horário. Porém, pela grande maioria dos intertravados terem sido instalados nas áreas sombreadas, a grama escolhida para nascer neste piso não atinge um crescimento regular, pois, a batatais é uma espécie de forração que prefere sol direto. Assim, na presença de eventuais falhas da grama, os intertravados ficam em contato direto com a areia, não se fixando perfeitamente e potencializando riscos de acidentes.

\subsubsection{Acessibilidade e Desenho Universal}

Na primeira visita, foi possível registrar a sensação de que em grande parte a praça é positiva em relação ao quesito acessibilidade. Para a análise técnica foi aplicado o checklist de Santiago et al (2016) tendo como parâmetro a NBR 9050:2015. A fim de detalhar a justificativa dos julgamentos "adequado" e "inadequado", foi adicionada uma coluna de observações.

Tabela 1: Checklist de acessibilidade

\begin{tabular}{|l|l|l|}
\hline PASSEIO & Sim & \multicolumn{2}{|c|}{ Adequado } \\
\hline Existência de revestimento de piso & $\begin{array}{l}\text { Granito flameado, placas de } \\
\text { concreto, e intertravado } \\
\text { piso grama }\end{array}$ & Adequado \\
\hline Tipo de pavimentação dos passeios; & $\begin{array}{l}\text { Algumas poucas peças } \\
\text { necessitando de }\end{array}$ & Adequado \\
\hline Estado de conservação; & &
\end{tabular}




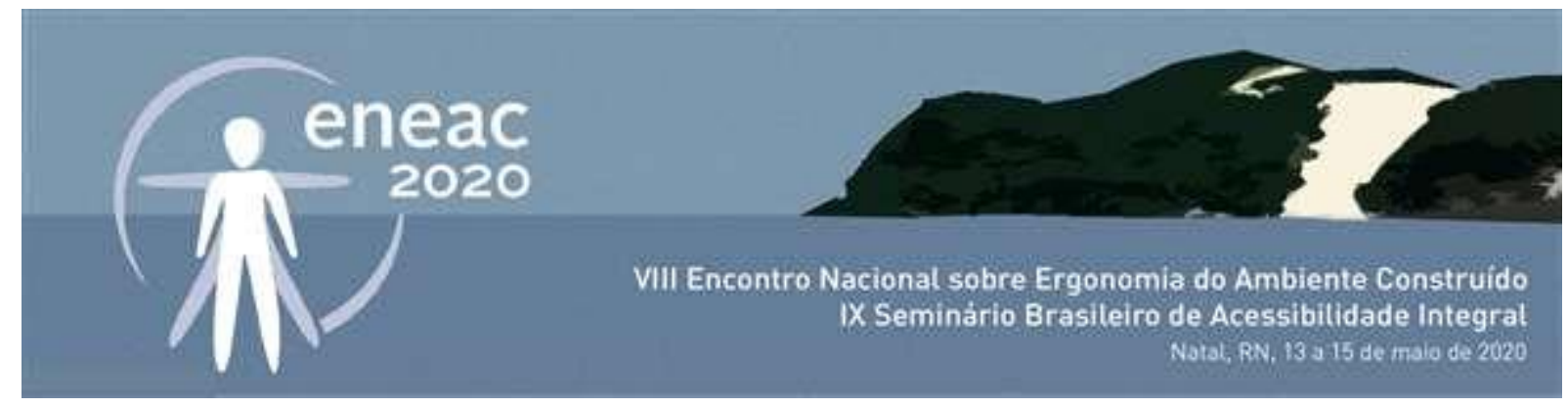

\begin{tabular}{|c|c|c|}
\hline & manutenção & \\
\hline Existência de pelo menos uma rota acessível; & \begin{tabular}{|l|} 
Piso tátil de alerta e \\
direcional com boa \\
instalação, e com contraste \\
de cor (amarelo - cinza) \\
\end{tabular} & Adequado \\
\hline Existência de passagens estreitas de circulação. & Largura mínima 2,90m & Adequado \\
\hline \multicolumn{3}{|l|}{ TRAVESSIAS E GUIAS REBAIXADAS } \\
\hline Largura mínima de 1,20m; & Sim & Adequado \\
\hline Inclinação máxima de 8,33\%; & Sim & Adequado \\
\hline Abas laterais da rampa com largura mínima de $50 \mathrm{~cm}$; & Sim & Adequado \\
\hline Abas laterais com inclinação recomendada de $10 \%$; & Sim & Adequado \\
\hline Desnível entre o término da rampa e o leito carroçável; & Nivelado & Adequado \\
\hline Localização da guia rebaixada junto á faixa de pedestre; & $\begin{array}{l}\text { Alinhado, porém não em } \\
\text { todas as esquinas }\end{array}$ & Inadequado \\
\hline Rampas alinhadas entre si dos lados opostos da via; & $\begin{array}{l}\text { Alinhado, porém não em } \\
\text { todas as esquinas }\end{array}$ & Inadequado \\
\hline Corte no canteiro central; & Não há canteiro central & $x$ \\
\hline \multicolumn{3}{|l|}{ ESTACIONAMENTO NA VIA PÚBLICA JUNTO ÀS PRAÇAS } \\
\hline Vagas reservadas para pessoas com deficiência (PcD); & Inexistente & Inadequado \\
\hline Vagas reservadas para idosos; & Inexistente & Inadequado \\
\hline $\begin{array}{l}\text { Nas vagas reservadas para PcD existência de espaço lateral de } \\
1,20 \mathrm{~m}\end{array}$ & Inexistente & Inadequado \\
\hline $\begin{array}{l}\text { Sinalização visual horizontal e vertical para os dois tipos de } \\
\text { vagas reservadas }\end{array}$ & Inexistente & Inadequado \\
\hline Localização das vagas reservadas próxima aos pólos de atração. & Sim & Adequado \\
\hline \multicolumn{3}{|l|}{ VEGETAÇÃO } \\
\hline Existência de vegetação que interrompe a rota acessível; & Não & Adequado \\
\hline Existência de raízes que danificam o passeio; & Não & Adequado \\
\hline Existência de espécies espinhosas; & $\begin{array}{l}\text { Tronco e folhas da } \\
\text { Carnaúbas; tronco da } \\
\text { Painera (01 unidade na } \\
\text { praça) }\end{array}$ & Inadequado \\
\hline Existência de espécies venenosas; & Não & Adequado \\
\hline Espécies que liberam frutos ou resina sobre o piso; & $\begin{array}{l}\text { As Mangueiras e os } \\
\text { Coqueiros possuem frutos; } \\
\text { as Casuarinas, dispostas nas } \\
\text { extremidades da praça, } \\
\text { produzem pinhas; os } \\
\text { Jeriquitis soltam suas } \\
\text { sementes vermelhas } \\
\end{array}$ & Inadequado \\
\hline Existência de galhos podados deixando livre $2,10 \mathrm{~m}$. & $\operatorname{Sim}$ & Adequado \\
\hline \multicolumn{3}{|l|}{ SINALIZAÇÃO DE ALERTA } \\
\hline $\begin{array}{l}\text { Em torno dos obstáculos suspensos com altura entre } 0,60 \mathrm{~m} \text { e } \\
2,10 \mathrm{~m}\end{array}$ & Inexistente & Inadequado \\
\hline Nos rebaixamentos de calçadas & Sim (Figura 7) & Adequado \\
\hline No início e término de escadas & Não há escadas & $\mathrm{x}$ \\
\hline
\end{tabular}




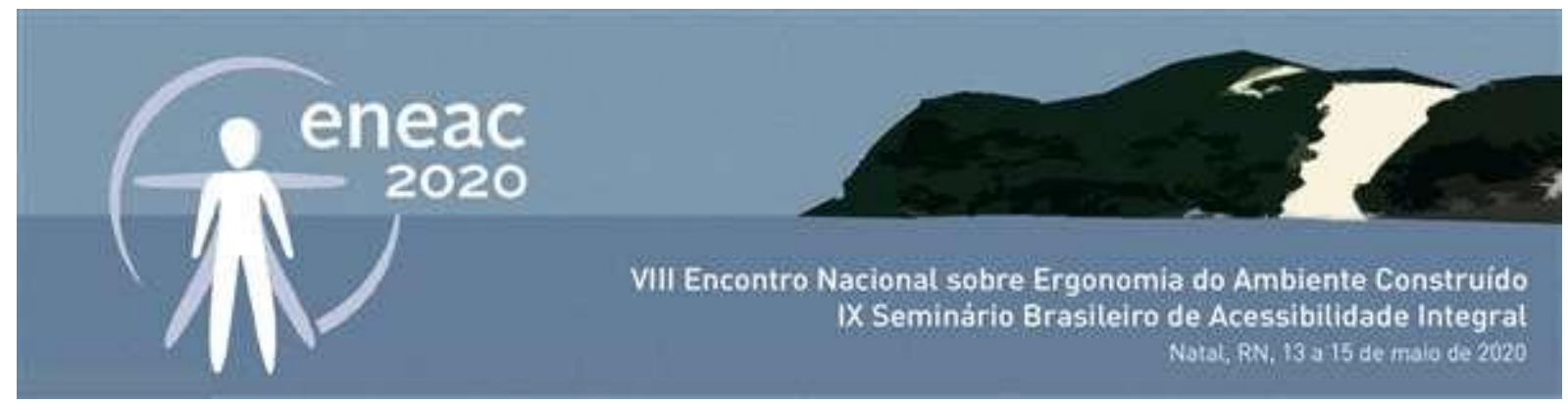

\begin{tabular}{|c|c|c|}
\hline No início e término de rampas & $\operatorname{Sim}$ & Adequado \\
\hline Junto a desníveis e paradas e ônibus & Não há paradas e ônibus & $\mathrm{x}$ \\
\hline \multicolumn{3}{|l|}{ SINALIZAÇÃO DIRECIONAL } \\
\hline Em áreas de circulação na ausência de guia de balizamento & Sim. & Adequado \\
\hline Em espaços amplos & Sim. & Adequado \\
\hline De forma transversal às guias rebaixadas & Sim. & Adequado \\
\hline Na divisa da calçada com o lote, quando não houver muro. & Não há essa configuração & $\mathrm{x}$ \\
\hline
\end{tabular}

Fonte: Modelo de SANTIAGO et al (2016) com dados levantados pelos autores (2020).

Figura 6: Tipos de pavimentação

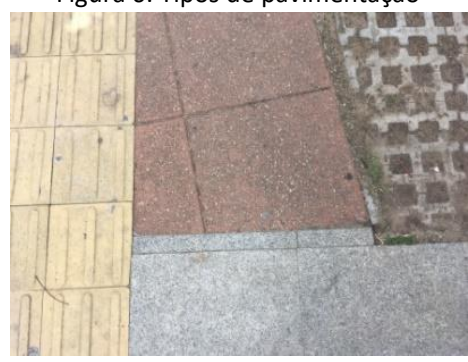

Fonte: Arquivo pesquisa.
Figura 7: Travessia e rebaixos de calçada

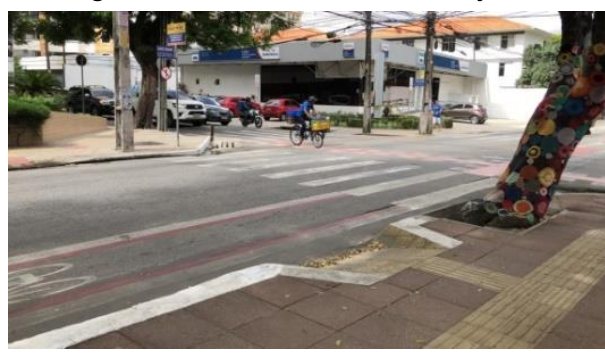

Fonte: Arquivo pesquisa.

A maioria dos pontos identificados como inadequados estão relacionados aos estacionamentos, a desalinhamentos de rampas com faixa de pedestre e às rampas dos quarteirões vizinhos. Entretanto, em geral, apresenta um bom desempenho, tendo como destaque a presença de uma rota acessível respeitando a norma.

\subsubsection{Avaliação de conforto ambiental}

Buscando contemplar diferentes situações da praça, foram escolhidos 13 pontos (Figura 02) para realizar as medições técnicas dos aspectos lumínicos, térmicos e acústicos. Na Tabela 2, estão compilados os resultados e destacados em vermelho as situações em desacordo com as respectivas normas vigentes.

Tabela 2: Conforto ambiental

\begin{tabular}{|c|c|c|c|c|c|c|c|c|c|c|}
\hline \multirow[b]{2}{*}{$\mathbf{P}$} & \multirow[b]{2}{*}{ ZONA } & \multicolumn{3}{|c|}{$10-11: 30$} & \multicolumn{3}{|c|}{$16-17 h$} & \multicolumn{3}{|c|}{$18: 40-19: 30$} \\
\hline & & $\begin{array}{l}\text { LUZ } \\
\text { (lux) }\end{array}$ & $\begin{array}{c}\text { TEMP } \\
\left({ }^{\circ} \mathrm{C}\right)\end{array}$ & $\begin{array}{c}\text { RUÍDO } \\
\text { (dB) }\end{array}$ & $\begin{array}{l}\text { LUZ } \\
\text { (lux) }\end{array}$ & $\begin{array}{l}\text { TEMP } \\
\left({ }^{\circ} \mathrm{C}\right)\end{array}$ & $\begin{array}{c}\text { RUÍDO } \\
\text { (dB) }\end{array}$ & $\begin{array}{l}\text { LUZ } \\
\text { (lux) }\end{array}$ & $\begin{array}{l}\text { TEMP } \\
\left({ }^{\circ} \mathrm{C}\right)\end{array}$ & $\begin{array}{c}\text { RUÍDO } \\
\text { (dB) }\end{array}$ \\
\hline 1 & Parquinho & 107600 & 31,4 & 57 & 4320 & 30 & $56,3-66$ & 23 & 28,8 & 62 \\
\hline 2 & Largo & 108000 & 33 & 56 & 6200 & 30,1 & 60 & 54 & 28,8 & 60 \\
\hline 3 & Banco & 7330 & 33,3 & 55 & 1240 & 30,9 & 63 & 1 & 28,9 & 60 \\
\hline 4 & Arquibancada & 35800 & 33,4 & 55 & 44,5 & 30,5 & 63 & 225 & 28,9 & 64 \\
\hline 5 & $\begin{array}{l}\text { Zona de } \\
\text { skatistas }\end{array}$ & 26000 & 34,5 & 50 & 10800 & 30,9 & 65 & 16 & 28,9 & 80 \\
\hline 6 & Arquibancada & 30000 & 33,2 & 52 & 916 & 29 & 66 & 101 & 28,8 & 75 \\
\hline 7 & Arquibancada & 110000 & 32,4 & 56 & 4220 & 30,3 & 58,8 & 59 & 28,8 & 60 \\
\hline 8 & Academia & 960 & 34 & 63 & 2700 & 30,2 & 63,7 & 90 & 28,8 & 57 \\
\hline
\end{tabular}




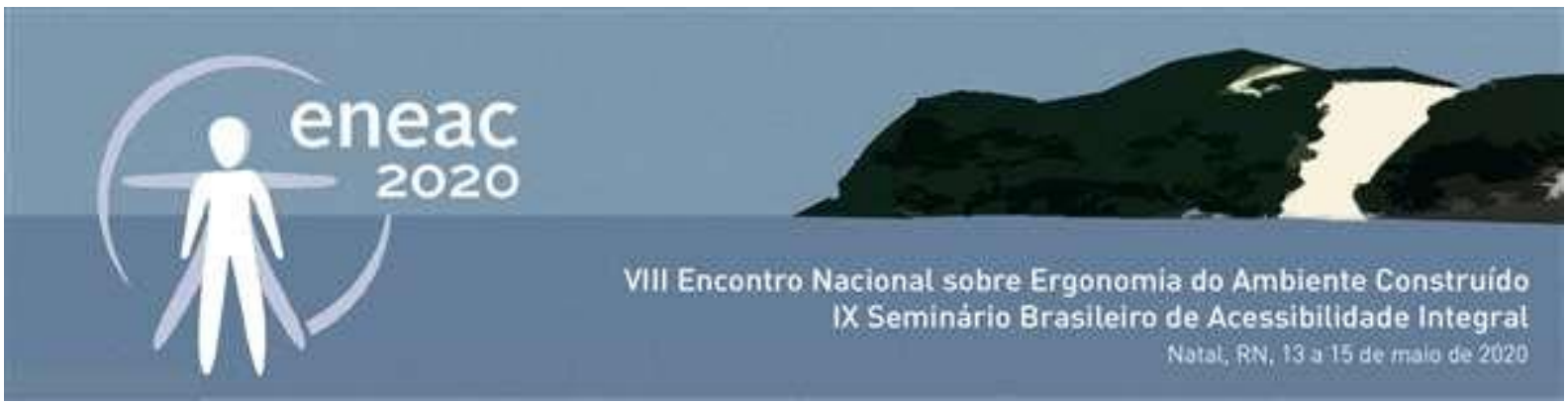

\begin{tabular}{|c|c|c|c|c|c|c|c|c|c|c|}
9 & Largo & 28000 & 33,2 & 57 & 6130 & 29,9 & 62,2 & 14 & 28,8 & 64 \\
\hline 10 & Banco & 2450 & 33,3 & 49 & 1480 & 30,3 & 59,9 & 4 & 28,9 & 55 \\
\hline 11 & Largo (vagão) & 80000 & 35 & 55 & 7600 & 30,6 & 57,4 & 19 & 28,9 & 73 \\
\hline 12 & Banco & 42000 & 36 & 60 & 6000 & 30,5 & 59,6 & 13 & 28,9 & 63 \\
\hline 13 & Bikes compart. & 15800 & 34 & 64 & 6110 & 30,3 & 58,7 & 35 & 29 & 65 \\
\hline
\end{tabular}

Lumínico (Digital Lux Meter MLM-1011/Padrão NBR9050 2015: mín 150 lux): Nos períodos da manhã e tarde, não há problemas relacionados ao baixo nível de luminosidade. Em contrapartida, a noite todos os pontos apresentaram problemas, principalmente nos localizados abaixo de árvores. É possível identificar a instalação de cordões de luz (Figura 9) ao longo do Largo na tentativa de solucionar esta questão, mas, segundos os parâmetros da norma, ainda está insuficiente.

Térmico (Termo Anemômetro Digital MDA-II/noite Padrão N17 20-23ํㅡ): O Largo, ampla área central, é atrativa para diferentes tipos de usos recreativos, porém usufruir deste espaço antes das $16 \mathrm{~h}$ é desconfortável devido à forte incidência solar e a ausência de coberturas artificiais ou naturais. Nos demais pontos da praça, há uma variação de situações devido à presença das árvores de médio e grande porte que proporcionam sombras.

Normalmente, a N17 é a norma responsável por ser parâmetro de medição de temperatura indica que o ideal entre 20 e $23^{\circ} \mathrm{C}$ para ambientes internos de trabalho; essa referência não se aplica a essa condição, por tratar-se de uma praça localizada no nordeste brasileiro. Segundo Freitas (2008), é possível considerar que temperaturas próximas a $25^{\circ} \mathrm{C}$ seria uma melhor referência para sensação de bem-estar. Mesmo com esse ponderamento da medida, todos os pontos foram diagnosticados como acima do valor estimado.

Acústico (Decibelímetro digital MSL-1325/Padrão NBR 10152: máx. 60 dB dia e 55 dB): Em geral, a praça é um espaço confortável em relação aos ruídos. Os picos registrados na tabela se referem a momentos específicos em que carros passavam na rua, pessoas estavam próximas conversando e/ou jovens estavam brincando de skates. Analisando os dados coletados é possível constatar que o período de maior movimento é o noturno.

\subsection{Avaliação do ambiente em uso}

A fim de analisar os arranjos espaciais, foi utilizado o Mapa Comportamental (Figura 8), onde o observador se posicionou em um ponto fixo, em três diferentes turnos e registrou os fluxos e as atividades exercidas, diferenciando o perfil do público observado através de uma sistematização compilada em uma legenda. 

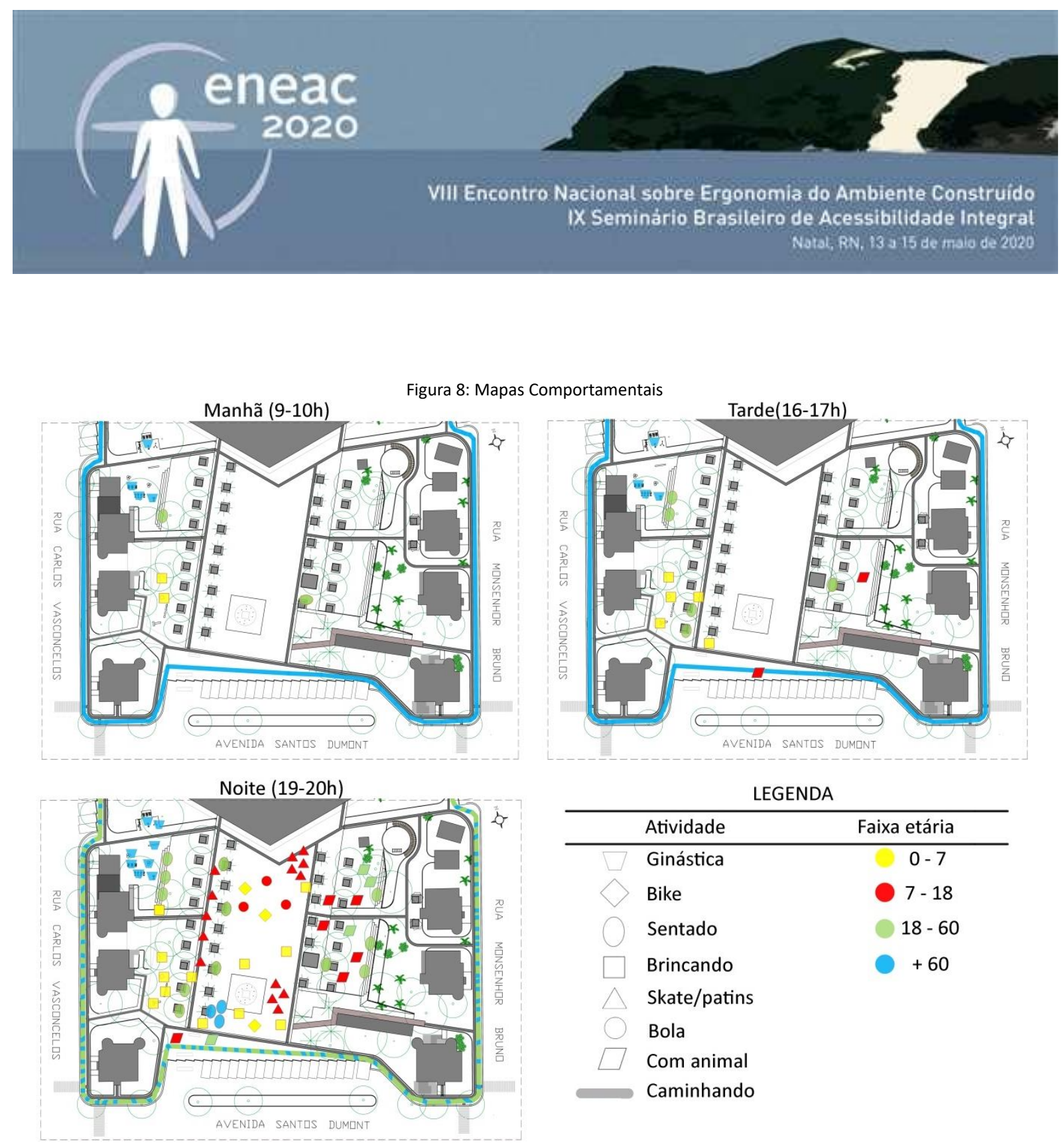

Fonte: Elaborados pelos autores

No momento da manhã, evidenciou-se a ocupação pelo público mais idoso com o uso da academia ao ar livre e das áreas mais periféricas para caminhar, com tímida presença de crianças na área do parquinho e de alguns adultos nos bancos mais sombreados. À tarde, conforme a incidência solar ia ficando mais branda, o uso da academia e da calçada para atividades físicas se repetia, mas a presença de crianças até 6 anos já era mais significativa no parquinho e nas áreas próximas. Já o período noturno, demostrou-se como o de maior ápice de movimentação com uso intenso da área central por crianças de todas as faixas etárias e adolescentes praticando variados tipos de atividades (Figura 9). Enquanto isso, adultos e idosos se concentram nos bancos conversando, por vezes, observando as crianças. A presença de animais domésticos, principalmente cachorros, é também um uso em destaque nesse período. 


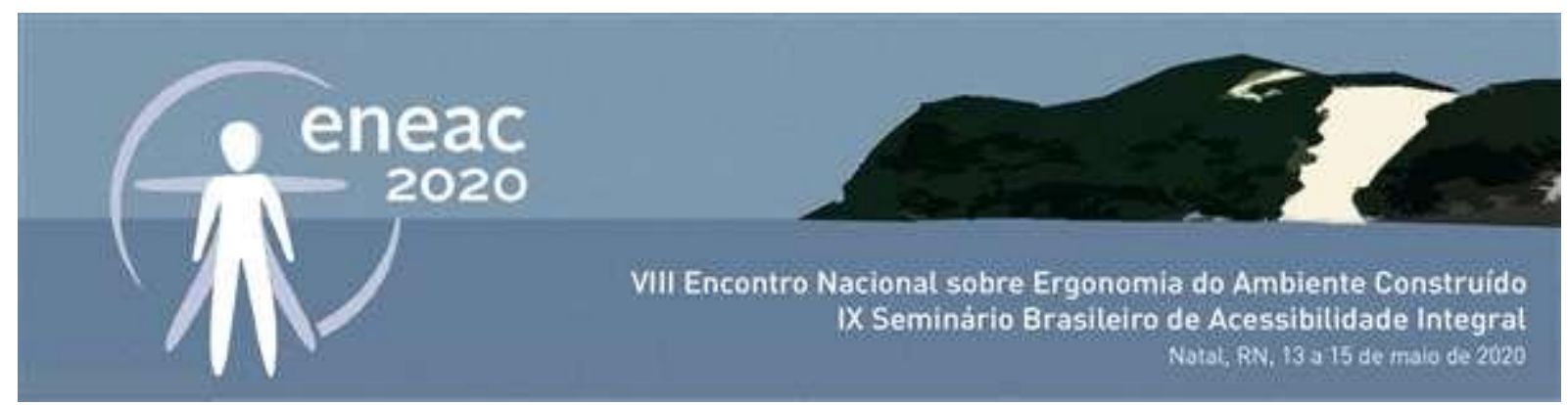

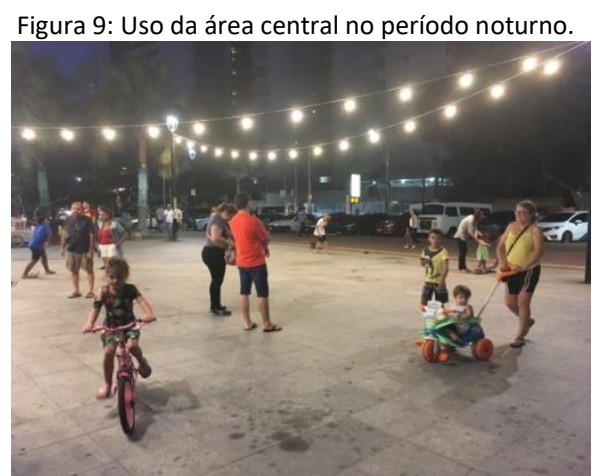

Fonte: Arquivo pesquisa.

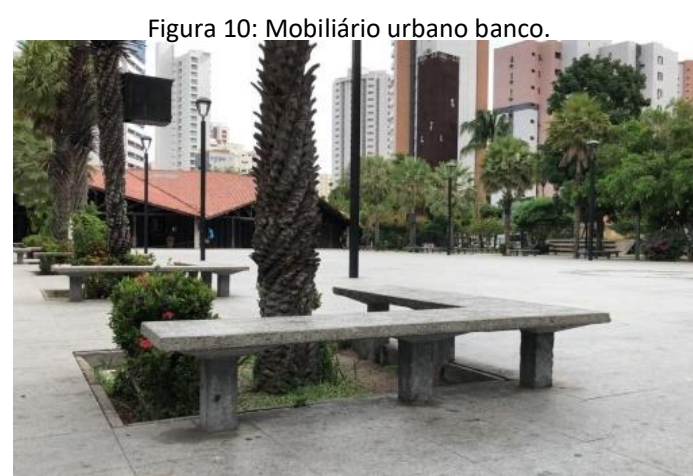

Fonte: Arquivo pesquisa.

Aproximando a escala, a pesquisa analisa o mobiliário urbano banco (Figura 10), presente em toda a extensão do recorte em estudo a fim de compreender como este favorece ou não o uso do ambiente. Compostos por granilite retangular, possuem altura $(39 \mathrm{~cm})$ e profundidade $(50 \mathrm{~cm})$ adequadas para o público adulto e estão distribuídos de forma que atendem à demanda de uso no horário de pico (noturno).

O formato em "L" favorece o uso do mobiliário (bancos) por grupos distintos, não induzindo um excesso de aproximação física com desconhecidos, respeitando o Espaço Pessoal de cada indivíduo, que segundo Sommer (1969), refere-se a uma área com limites invisíveis que cercam o corpo das pessoas. Além disso, por não possuírem braços nem encostos, este formato dos bancos permite diversos tipos de acomodações, inclusive deitado, sendo possível uma visão plena dos responsáveis pelas crianças. Em contrapartida, para o público idoso, não é uma opção interessante nem confortável, por necessitarem de pontos de apoio para levantar e sentar.

\subsection{Percepção do ambiente}

Sendo o público infantil o foco da pesquisa, foram aplicados dois diferentes métodos dando ênfase à percepção espacial sob a ótica da criança. Por tratar-se de um grupo dependente dos respectivos responsáveis, a opinião dos pais foi tratada como relevante na análise.

A Constelação de Atributos, idealizada por Moles (1968), se baseia na estruturação de duas perguntas sobre espaço (imaginário e real) e sistematização das respostas em um gráfico que considera a classificação de atributos e a disposição destes a partir de uma distância psicológica. Na presente pesquisa, as perguntas foram aplicadas aos pais das crianças que utilizavam a praça, sendo elas: "Que imagens ou ideias Ihe vem à cabeça quando pensa em um espaço público bom para as crianças?" (imaginário) e "Que imagem ou ideia Ihe vem à cabeça quando você pensa na Praça Luiza Távora?" (real). As respostas foram registradas através de gravação de áudio e posteriormente transcritas, traduzidas em atributos e classificadas em grupos. Para auxiliar na organização das tabelas e dos gráficos, foi utilizada a ferramenta online da UNICAMP que transpôs para o formato digital e editável a ferramenta Constelação de Atributos. 


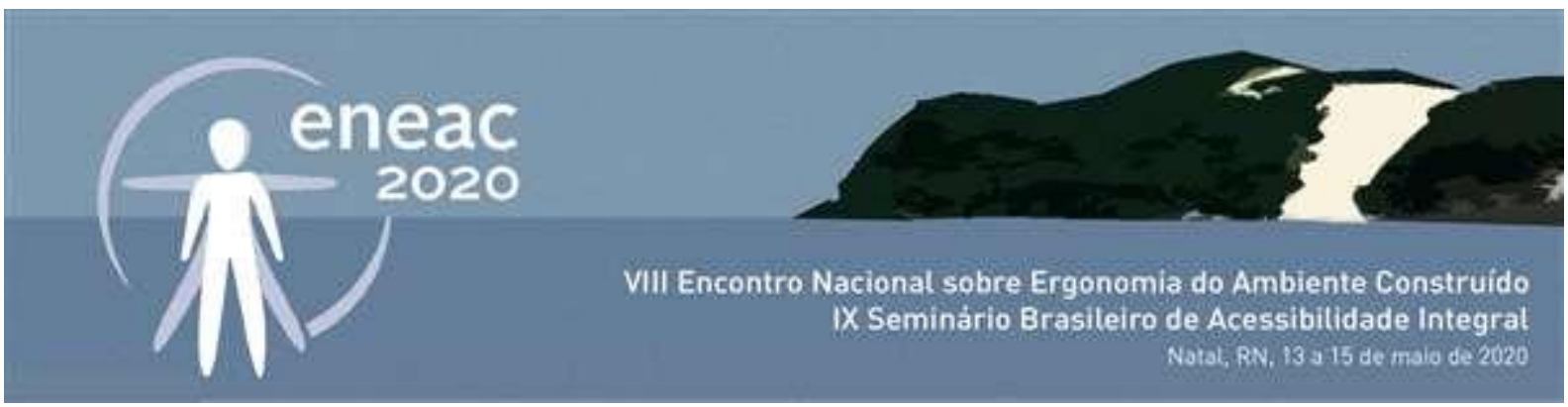

Tabela 3: Tabela de Atributos Associados ao Ambiente Imaginário

\begin{tabular}{|c|c|c|c|c|}
\hline CATEGORIAS & $\begin{array}{l}\text { ATRIBUTOS ASSOCIADOS AO } \\
\text { AMBIENTE }\end{array}$ & $\begin{array}{c}\text { QUANT. } \\
\text { OCORRÊNCIAS }\end{array}$ & CLASSIFICAÇÃO & $\begin{array}{c}\text { DIST. } \\
\text { PSICOLÓGICA }\end{array}$ \\
\hline \multirow{3}{*}{$\begin{array}{l}\text { Conforto } \\
\text { Ambiental }\end{array}$} & Arborizado & 11 & 1 & 0.74 \\
\hline & Amplo & 9 & 2 & 0.8 \\
\hline & Aconchegante/freca & 2 & 7 & 1.7 \\
\hline & SUBTOTAL & 22 & & \\
\hline \multirow{5}{*}{ Infraestrutura } & Brinquedos & 8 & 3 & 0.83 \\
\hline & Segurança civil & 5 & 4 & 1 \\
\hline & Acessivel & 2 & 7 & 1.7 \\
\hline & Segurança viária & 2 & 7 & 1.7 \\
\hline & Opções de alimentação & 1 & 8 & 3.3 \\
\hline \multicolumn{2}{|r|}{ SUBTOTAL } & 18 & & \\
\hline Manutenção & Limpo & 2 & 7 & 1.7 \\
\hline \multicolumn{2}{|r|}{ SUBTOTAL } & 2 & & \\
\hline \multirow{3}{*}{ Social } & Familiar & 4 & 5 & 1.1 \\
\hline & Receptiva a animais & 3 & 6 & 1.3 \\
\hline & Espaço Infantil & 1 & 8 & 3.3 \\
\hline \multicolumn{2}{|r|}{ SUBTOTAL } & 8 & & \\
\hline \multicolumn{2}{|c|}{ TOTAL DE RESPOSTAS } & 50 & & \\
\hline \multicolumn{2}{|c|}{ TOTAL DE ENTREVISTADOS } & 20 & & \\
\hline
\end{tabular}

Fonte: Elaborada pelos autores.

Gráficos 01 e 02: Constelação de Atributos (Imaginário e Real)

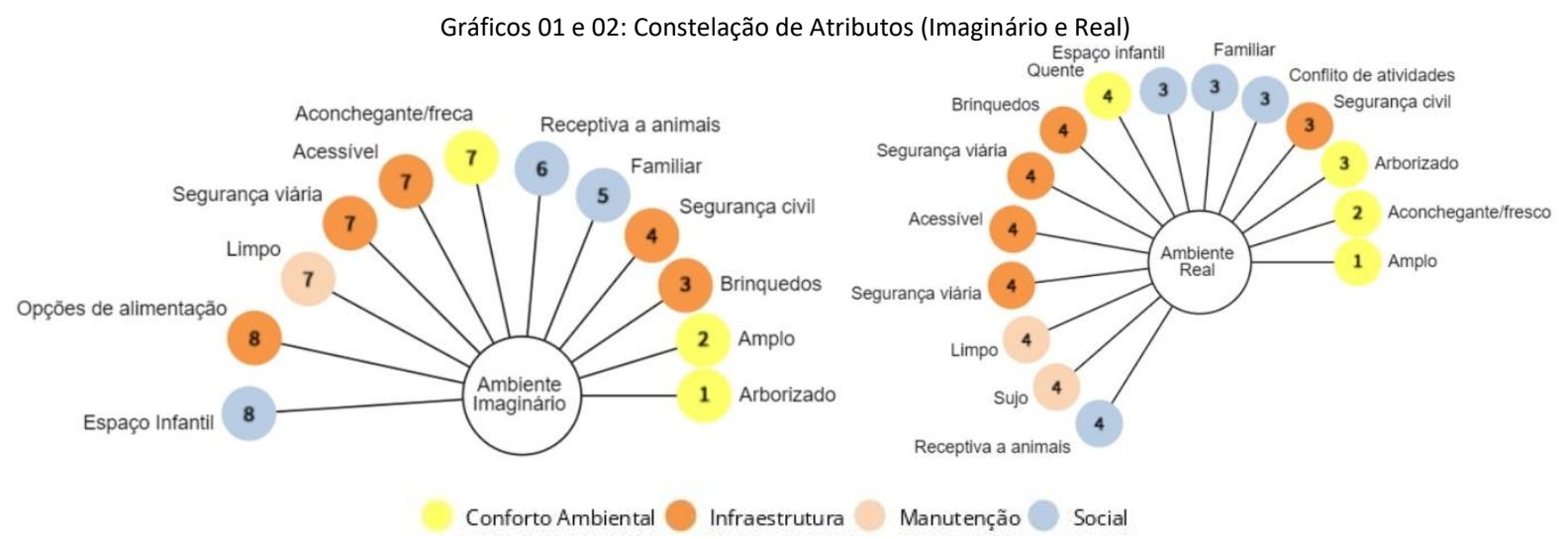

Fonte: Elaborada pelos autores.

Os atributos foram classificados em quatro categorias (conforto ambiental, infraestrutura, manutenção e social) e diferenciados por cores. No gráfico, quando mais próximos estiverem os atributos do centro, ou seja, quando menor for a distância psicológica, maior é a quantidade de ocorrência. $O$ desejo por um lugar arborizado foi destaque, sendo o segundo colocado, amplitude do espaço e a presença de brinquedos, mobiliários lúdicos. 


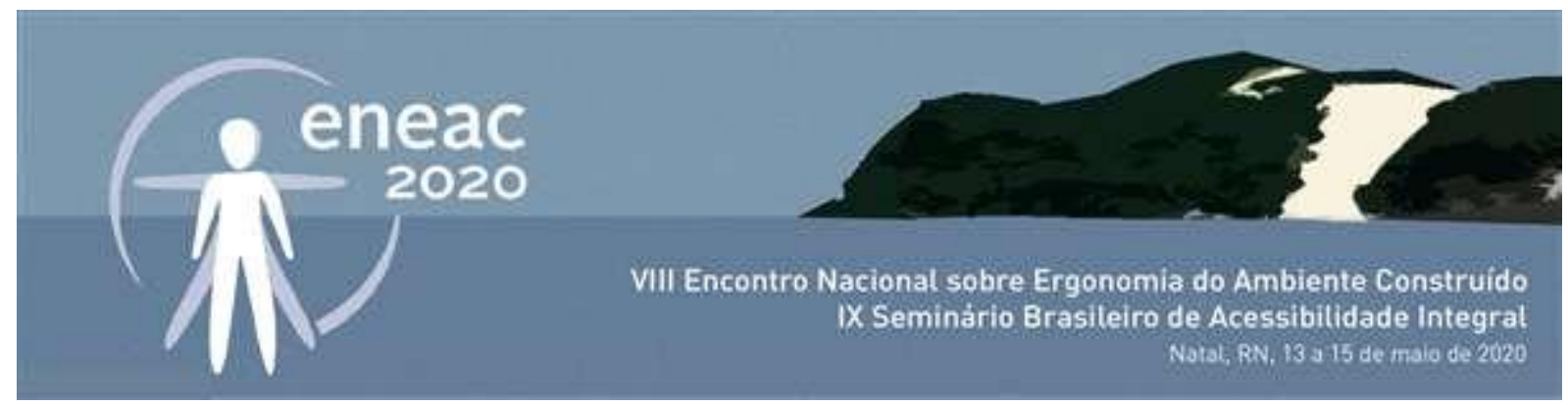

Tabela 4: Tabela de Atributos Associados ao Ambiente Real

\begin{tabular}{|c|c|c|c|c|}
\hline CATEGORIAS & $\begin{array}{c}\text { ATRIBUTOS ASSOCIADOS AO } \\
\text { AMBIENTE }\end{array}$ & $\begin{array}{l}\text { QUANT. } \\
\text { OCORRÊNCIAS }\end{array}$ & CLASSIFICAÇÃO & $\begin{array}{c}\text { DIST. } \\
\text { PSICOLÓGICA }\end{array}$ \\
\hline \multirow{4}{*}{$\begin{array}{l}\text { Conforto } \\
\text { Ambiental }\end{array}$} & Amplo & 8 & 1 & 0.7 \\
\hline & Aconchegante/fresco & 4 & 2 & 0.89 \\
\hline & Arborizado & 2 & 3 & 1.2 \\
\hline & Quente & 1 & 4 & 1.9 \\
\hline \multicolumn{2}{|r|}{ SUBTOTAL } & 15 & & \\
\hline \multirow{5}{*}{ Infraestrutura } & Segurança civil & 2 & 3 & 1.2 \\
\hline & Acessível & 1 & 4 & 1.9 \\
\hline & Brinquedos & 1 & 4 & 1.9 \\
\hline & Segurança viária & 1 & 4 & 1.9 \\
\hline & Segurança viária & 1 & 4 & 1.9 \\
\hline \multicolumn{2}{|r|}{ SUBTOTAL } & 6 & & \\
\hline \multirow{2}{*}{ Manutenção } & Limpo & 1 & 4 & 1.9 \\
\hline & Sujo & 1 & 4 & 1.9 \\
\hline \multicolumn{2}{|r|}{ SUBTOTAL } & 2 & & \\
\hline \multirow{4}{*}{ Social } & Conflito de atividades & 2 & 3 & 1.2 \\
\hline & Espaço infantil & 2 & 3 & 1.2 \\
\hline & Familiar & 2 & 3 & 1.2 \\
\hline & Receptiva a animais & 1 & 4 & 1.9 \\
\hline \multicolumn{2}{|r|}{ SUBTOTAL } & 7 & & \\
\hline \multicolumn{2}{|c|}{ TOTAL DE RESPOSTAS } & 30 & & \\
\hline \multicolumn{2}{|c|}{ TOTAL DE ENTREVISTADOS } & 20 & & \\
\hline
\end{tabular}

Fonte: Elaborada pelos autores.

Quando a pergunta se volta para o ambiente real, ou seja, a Praça Luiza Távora, é possível perceber que a amplitude do lugar é a característica mais atrativa, vindo em seguida à associação positiva com a forte presença de árvores, elementos paisagísticos existentes. O atributo "conflito de atividades" refere-se a uma insatisfação dos pais na prática de atividades como jogar bola e a prática de skate que podem oferecer risco de segurança às crianças mais novas, tendo em vista que, no período noturno todos os públicos ocupam a área central simultaneamente.

Além das respostas compiladas para a elaboração da Constelação de Atributos, nas entrevistas, foi possível compreender algumas motivações dos pais em frequentar a Praça, dentre elas estavam: ser um lugar em que brincavam quando criança (memória afetiva), gostar da vitalidade do lugar e das edificações históricas presentes. Outro ponto de atratividade foi o "Espaço Mais Infância Ceará", o qual funciona em uma das edificações históricas da praça e realiza mensalmente uma programação gratuita direcionada, principalmente, para a primeira infância.

Como forma de ouvir as crianças que utilizam a Praça Luiza Távora, foi pensada a aplicação do Poema dos Desejos de Henry Sanoff (1991;1995), método que, a partir de uma pergunta norteadora, orienta o entrevistado na elaboração de uma resposta através de desenho, escrita e/ou fala. Foram levados papeis, canetas e lápis de cor para que as crianças pudessem responder a seguinte pergunta: "Como você gostaria que fosse a Praça Luiza Távora?". 


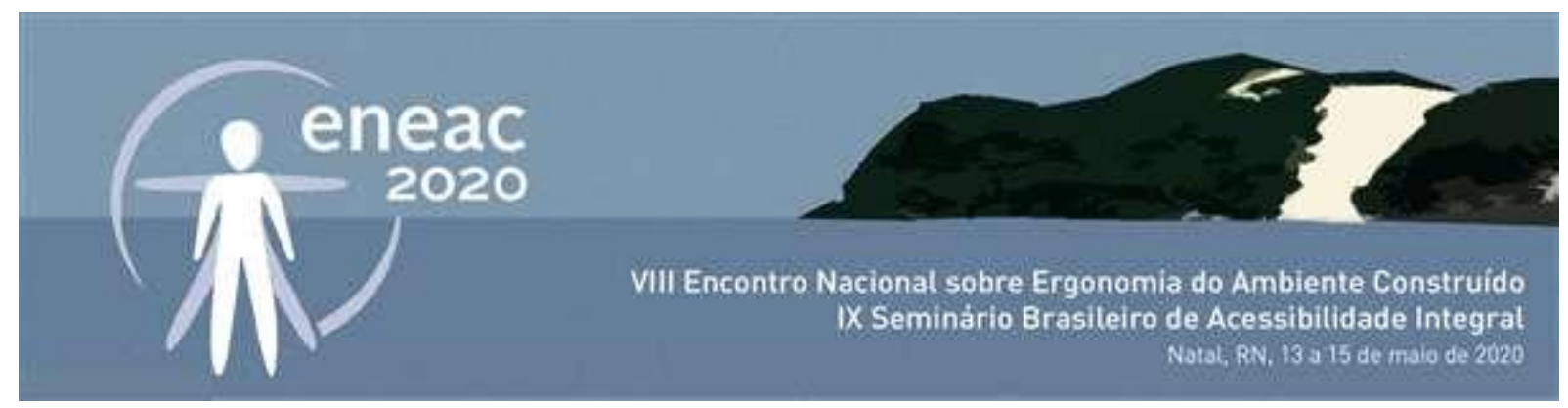

Entretanto, no momento da aplicação do método, foi identificada uma dificuldade em acessar as crianças, as quais estavam envolvidas com atividades lúdicas e dispersas para responder a atividade. Desta forma, houve a necessidade de adaptação da estratégia, sendo feita a pergunta, sob a permissão do responsável, de maneira verbal para doze crianças a cima de sete anos. $O$ universo de respostas foi amplo, destacando-se o desejo por mais brinquedos (balanço, gangorra, pula-pula), mas também surgindo sugestões como aulas de música e pontos de alimentação gratuita.

\subsection{Diagnóstico e recomendações}

A partir da aplicação de métodos foi possível confirmar o bom desempenho da Praça Luiza Távora em aspectos de acessibilidade, atratividade e configuração espacial por ser um espaço amplo, que transmite sensação de segurança, conforto, promove contato com elementos naturais e possui vitalidade através de atividades recreativas regulares. Todos esses aspectos auxiliam na compreensão do senso de apropriação desenvolvido nos moradores da cidade de Fortaleza para com o lugar, sendo um exemplo positivo de espaço público para todas as idades, inclusive para o público infantil.

Os problemas diagnosticados foram listados na Tabela 5 com a indicação das respectivas recomendações.

Tabela 5: Diagnóstico e Recomendações

\begin{tabular}{|l|l|}
\hline \multicolumn{1}{|c|}{ Diagnóstico } & \multicolumn{1}{|c|}{ Recomendações } \\
\hline $\begin{array}{l}\text { A alta temperatura no período da tarde inviabiliza a } \\
\text { ocupação do espaço }\end{array}$ & $\begin{array}{l}\text { Disposição de mais elementos que projetem sombra } \\
\text { (árvores, pergolados...) }\end{array}$ \\
\hline Poucos brinquedos para crianças & $\begin{array}{l}\text { Instalar mais mobiliários lúdicos, não necessariamente } \\
\text { brinquedos padrões }\end{array}$ \\
\hline Baixo nível de luminância no período noturno & $\begin{array}{l}\text { Instalar pontos de iluminação que atenta a exigência a } \\
\text { NBR 9050 2015 }\end{array}$ \\
\hline $\begin{array}{l}\text { Inexistência de sinalização em torno de obstáculos } \\
\text { suspensos com altura entre 0,60m e 2,10m }\end{array}$ & $\begin{array}{l}\text { Instalar piso tátil de alerta conforme orientações da NBR } \\
\text { 9050 2015 }\end{array}$ \\
\hline Estacionamento não considerando vagas especiais & $\begin{array}{l}\text { Incluir instalação de comunicação vertical e horizontal } \\
\text { que referencie as respectivas vagas reservadas }\end{array}$ \\
\hline Grama falha na área em que há intertravado piso grama & $\begin{array}{l}\text { Substituir espécie de forração ou substituir pavimentação } \\
\text { por material com superfície mais regular e porcentagem } \\
\text { de permeabilidade }\end{array}$ \\
\hline Rampa de vagão de trem e fonte quebrados & \begin{tabular}{l} 
Fazer manutenção \\
\hline
\end{tabular}
\end{tabular}

Fonte: Elaborada pelos autores.

\section{CONSIDERAÇÕES FINAIS}

A aplicação da MEAC na Praça Luiza Távora permitiu a análise técnica detalhada e foi ferramenta eficaz na compreensão das motivações de apropriação urbana atípica, de todo modo considerado positiva neste espaço público do bairro Aldeota.

$\mathrm{Na}$ etapa de Percepção do Ambiente destacou-se a dificuldade em acessar as crianças abaixo de sete anos no processo de escuta, sendo uma questão que a pesquisa conclui como fundamental de ser explorada em posteriores estudos a fim de proporcionar processos participativos mais inclusivos com o público infantil. 


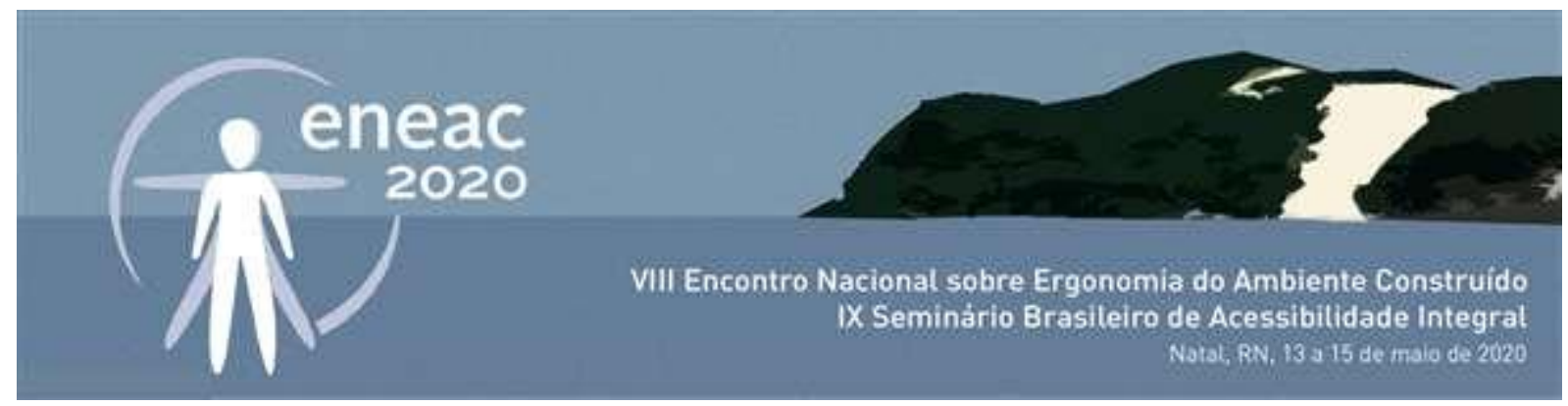

Este trabalho integra uma pesquisa mais ampla que trata dos espaços públicos para lazer infantil. Os resultados alcançados colaboraram fortemente para a promoção de ajustes na pesquisa principal, notadamente na definição de ferramentas e faixas etárias para estudos da percepção ambiental dos usuários dos espaços.

\section{REFERÊNCIAS}

ALEX, S. Projeto da praça: convívio e exclusão no espaço público. São Paulo: Editora Senac São Paulo, 2011.

ASSOCIAÇÃO BRASILEIRA DE NORMAS TÉCNICAS. NBR 9.050: Acessibilidade de pessoas portadoras de deficiências e edificações, espaço, mobiliário e equipamentos urbanos. Rio de Janeiro, 2015.

ASSOCIAÇÃO BRASILEIRA DE NORMAS TÉCNICAS. NBR 10152: Nível de ruído para conforto acústico. Rio de Janeiro, 2000.

BAIERL, L.F. Medo Social: da violência ao invisível da violência. São Paulo: Cortez, 2004.

FREITAS, R. M. Entre mitos e limites: as possibilidades do adensamento construtivo face à qualidade de vida no ambiente vurbano. 2005. Tese (Doutorado) Programa de Pesquisa e Pós-graduação em Arquitetura da Universidade Federal do RioGrande do Sul. Porto Alegre, 2005.

KORPELA, K. Children's environment. In: BECHTEL, R. B.; CHURCHMAN, A. (Ed.). Handbook of environmental psychology. New York: John Wiley \& Sons, 2001. p. 363-373.

LYNCH, K. The Image of the city. Cambridge: The M.I.T. Press, 1960.

MOLES, A. Sociodinámica de La cultura. Barcelona: Editora Gustavo Gili, 1968.

NR, Norma Regulamentadora Ministério do Trabalho e Emprego. NR-17: Ergonomia. 2018.

SANOFF, Henry. Visual Research Methods in Design. New York: Van Nostrand R 1991.

SANOFF, Henry. Creating Environments for Young Children. Mansfield, Ohio: BookMasters, Inc., 1995.

SANTIAGO, Z. M. P.; SANTIAGO, C.Q. de; SOARES, T. S. Acessibilidade no espaço público: o caso das praças de Fortaleza. RevistaErgodesign $\mathrm{HCl}$, [S.I.], v. 4, n. 2, p. 32-39, 2016.

SOMMER, R. Personal Space. Englewood Cliffs: Prentice-Hall, 1969.

UNICAMP. Ferramenta online de Constelação de Atributos. Disponível em: http://www.fec.unicamp.br/ confterm/. Acesso em: 08, março, 2020.

VILLAROUCO, Vilma. Construindo uma metodologia de avaliação ergonômica do ambiente. In: Anais do XV Congresso Brasileiro de Ergonomia - ABERGO, Bahia, 2008. 